Comunicações Breves

Brief Communication

Bruna Rainho Rocha ${ }^{1}$ (1)

Andus Wing-Kuen Wong ${ }^{2}$

Estella Pui-Man $\mathrm{Ma}^{3}$

Mara Behlau ${ }^{1}$ (C)

Descritores

Voz

Estudos de Validação

Comunicação

Qualidade da Voz

Fonoaudiologia

Questionários

Estudos de Avaliação

Tradução (produto)

Keywords

Voice

Validation Studies

Communication

Voice Quality

Speech, Language and Hearing

Sciences

Questionnaires

Evaluation Studies

Translations

Endereço para correspondência:

Bruna Rainho Rocha

Programa de Pós-graduação em

Distúrbios da Comunicação Humana,

Departamento de Fonoaudiologia,

Universidade Federal de São Paulo -

UNIFESP

Rua Botucatu, 802, Vila Clementino, São Paulo (SP), Brasil, CEP: 04023-

901.

E-mail: b.rocha@unifesp.br

Recebido em: Novembro 24, 2020

Aceito em: Julho 16, 2021

\section{Equivalência cultural da versão brasileira do protocolo Speech-Specific Reinvestment Scale- SSRS}

\author{
Cross-cultural adaptation of the Brazilian \\ version of the Speech-Specific Reinvestment \\ Scale - SSRS
}

\section{RESUMO}

Objetivo: Realizar a equivalência cultural da versão brasileira da escala SSRS, por meio de sua adaptação cultural e linguística. Método: Após tradução da SSRS para o português brasileiro e retro tradução para o inglês, os itens foram comparados com o instrumento original. As discrepâncias existentes foram modificadas por consenso por um comitê de fonoaudiólogos, resultando na Escala de Reinvestimento Específico na Fala - EREF. A EREF tem 39 questões e seis alternativas na chave de resposta: "discordo totalmente", "discordo", "discordo ligeiramente", "concordo ligeiramente", "concordo" e "concordo totalmente". A pontuação é a soma das pontuações médias de cada subdimensão da escala, sendo que os itens negativos não entram na contabilidade ou exigem pontuação reversa. Para a equivalência cultural, a EREF foi aplicada em um total de 74 profissionais em exercício de atividade envolvendo comunicação com público, falantes do português brasileiro como primeira língua, com acréscimo da opção "não aplicável" na chave de respostas, para identificação de questões não compreendidas ou não apropriadas para a população alvo e cultura brasileira. Resultados: A escala foi inicialmente aplicada em 56 participantes. Treze encontraram dificuldade para o preenchimento de 27 questões. Após a adaptação da tradução das sentenças não compreendidas ou consideradas inapropriadas, a EREF modificada foi aplicada em mais 13 respondentes e não foram encontradas barreiras culturais e/ou conceituais. Conclusão: Foi verificada equivalência cultural entre a SSRS e sua versão traduzida para o português brasileiro, a EREF. As próximas etapas para validação da EREF para o Português Brasileiro serão realizadas com a conclusão desta fase.

\begin{abstract}
Purpose: To present the cross-cultural equivalence of the Brazilian version of the Specific Reinvestment Scale in Speech - SRRS through its cultural and linguistic adaptation. Methods: After the SSRS was translated into Brazilian Portuguese, the back-translation was done and the items were compared. Discrepancies were modified by consensus of a committee of SLPs. The SSRS, named "Escala de Reinvestimento Específico na Fala-EREF", has 39 questions and six alternatives in the answer key: "strongly disagree", "disagree", "slightly disagree", "slightly agree", "agree" and "strongly agree". The mean score is computed by the sum of each subdimension. Negative items may not be included in the EREF scoring or need reversed coding process before using them. For cultural equivalence, the EREF was applied to a total of 74 professionals working in an activity involving communication with the public, speakers of Brazilian Portuguese as a first language, with an extra item in the answer key - "not applicable" - to identify issues that might not have been understood or were not appropriate for the target population and Brazilian culture. Results: The scale was initially applied to 56 participants, thirteen of whom found it difficult to complete 27 questions. After adaptation of those sentences, the modified EREF was applied to 13 more participants and no further cultural and / or conceptual barriers were found. Conclusion: Cultural equivalence between the SSRS and its translated version to Brazilian Portuguese - EREF was verified. The next steps for the EREF validation for Brazilian Portuguese will be carried out.
\end{abstract}

Trabalho realizado na Universidade Federal de São Paulo - UNIFESP - São Paulo (SP), Brasil

${ }^{1}$ Programa de Pós-graduação em Distúrbios da Comunicação Humana, Departamento de Fonoaudiologia, Universidade Federal de São Paulo - UNIFESP - São Paulo (SP), Brasil

${ }^{2}$ Nam Shan Psychology Laboratory, Department of Social and Behavioural Sciences, University of Hong Kong, Hong Kong, China

${ }^{3}$ Division of Speech and Hearing Sciences, University of Hong Kong, Hong Kong, China

Fonte de financiamento: nada a declarar.

Conflito de interesses: nada a declarar 


\section{INTRODUÇÃO}

A comunicação é fundamental em todas as esferas de relacionamento humano, seja nas relações pessoais, empresariais ou educacionais. $\mathrm{O}$ termo comunicar é proveniente do latim - communicare - que significa "tornar comum"(1). Ou seja, a comunicação é eficiente quando o interlocutor consegue transmitir a mensagem desejada ao receptor, que a compreende integralmente. Essa mensagem pode ser codificada de diversas maneiras, sendo elas verbais - por meio da fala ou escrita - ou não-verbais - como, por exemplo, pelo uso de gestos e expressões faciais. Em um discurso oral, a linguagem verbal e a não-verbal estão sempre presentes, quer o interlocutor esteja ciente delas ou não e para uma boa comunicação, é importante que uma esteja em concordância com a outra, se completando e em coerência.

A comunicação sempre foi importante e tem se destacado cada vez mais, visto que as profissões que utilizam a comunicação como principal fator do desenvolvimento do seu trabalho estão aumentando em detrimento dos trabalhos manuais ${ }^{(2)}$. Já ao final do século XX, verificou-se que $62 \%$ da força de trabalho baseava seu sustento nas habilidades de comunicação - audição, voz, fala e linguagem - e os $38 \%$ que não utilizavam a comunicação para o trabalho - como agricultores e operários - necessitavam dela para adequada inserção na sociedade. Ou seja, a comunicação é fundamental para o crescimento profissional e pessoal e cada vez mais a sua competência é exigida na sociedade ${ }^{(3)}$.

Desenvolver as habilidades de comunicação e tornar a linguagem verbal e não-verbal em concordância demanda treino e conhecimento. Para poder auxiliar aqueles com dificuldade e tornar esse treino mais específico e direto, é importante avaliar as habilidades envolvidas na comunicação, inclusive com protocolos de autoavaliação.

Os protocolos de autoavaliação são considerados importantes ferramentas de mensuração do conhecimento do indivíduo sobre o impacto de sua condição - seja ela um problema ou algo a ser aprimorado - em suas relações sociais e profissionais ${ }^{(4)}$. Apesar de seu uso frequente, a maioria deles ainda é direcionada para questões de saúde, como os questionários de qualidade de vida. No Brasil, ainda há poucos instrumentos capazes de investigar a autoavaliação da comunicação de um indivíduo. Porém, tendo em vista a importância da comunicação, é imprescindível que esse panorama seja modificado.

A "Escala de Reinvestimento Específico na Fala - EREF" (Speech-Specific Reinvestment Scale - SSRS) ${ }^{(5)}$ é uma nova medida psicométrica que tem por objetivo quantificar a predisposição de alguém para exercer controle e monitoramento conscientes sobre a fala. Engloba questões não apenas do controle consciente sobre os movimentos da fala (por exemplo, movimento da língua, lábio e mandíbula), mas também o monitoramento consciente do conteúdo e da maneira de falar, assim como da movimentação facial e corporal para alcançar o objetivo final da comunicação, isto é, para permitir que o destinatário perceba e compreenda o discurso.

A escala foi desenvolvida com referência à Teoria de Reinvestimento $^{(6-8)}$ sobre controle do motor dos membros do corpo. De acordo com essa teoria as habilidades motoras requerem dois tipos de processamento: o implícito e o explícito. O primeiro é benéfico para habilidades motoras bem praticadas, relativamente automatizadas, trabalhando com o conhecimento já pré-estabelecido e requer poucos recursos de memória de atenção e de trabalho. Por outro lado, o segundo é baseado em regras e requer consideráveis recursos de atenção e memória de trabalho.

As pessoas podem ser reinvestidoras altas ou baixas e, as que reinvestem de modo elevado, têm maior tendência de falhar em situações estressantes que envolvem habilidades complexas e vinculadas a regras ${ }^{(6-8)}$. Assim, ao elaborar a escala SSRS, os autores tinham como hipótese que o traço de personalidade de predisposição da consciência do controle e monitoramento da fala estaria relacionado negativamente à performance na fala conversacional. Os resultados apontaram para a confirmação da hipótese.

Além disso, os resultados validaram quatro subdimensões da SSRS, uma de controle e três de monitoramento da fala: 1 . Subdimensão da autoconsciência do movimento da fala - ACMF, 2. Subdimensão da consciência pública da maneira de falar CPMF, 3. Subdimensão da consciência pública do conteúdo da fala - CPCF, 4. Subdimensão da consciência pública da movimentação durante a fala $-\mathrm{CPMF}^{(5)}$. A escala possibilita a avaliação das subdimensões de forma distinta ou conjunta, o que a torna ainda mais robusta para examinar quaisquer efeitos variáveis sobre desempenho da fala, inclusive não-verbais, conforme sugerido pela literatura da Teoria do Reinvestimento ${ }^{(9)}$.

Visto que a escala Speech-Specific Reinvestment Scale - SSRS $^{(5)}$ foi desenvolvida em inglês, para o uso em outras línguas deve ser traduzida e culturalmente adaptada de acordo com as regras internacionais do Scientific Advisory Committee of Medical Outcome Trust $t^{(10)}$

O objetivo deste estudo foi realizar a equivalência cultural da versão brasileira da escala SSRS, por meio de sua adaptação cultural e linguística.

É importante ressaltar que, por se tratar de uma escala nova, ainda não há repercussão de seu uso, embora seja de grande potencial. A adaptação brasileira é a primeira a ser realizada com o instrumento.

\section{MÉTODO}

Após a autorização formal dos autores para a utilização do instrumento Speech-Specific Reinvestment Scale - SSRS) ${ }^{(5)}$, a pesquisa foi aprovada pelo Comitê de Ética em Pesquisa da Universidade Federal de São Paulo/CEP UNIFESP (parecer $\mathrm{n}^{\circ}$ 4.356.465 e CAAE: 36606720.0.0000.5505). Todos os participantes assinaram o Termo de Consentimento Livre e Esclarecido - TCLE.

Participaram profissionais adultos em exercício de atividade envolvendo comunicação oral com público, com experiência mínima de três meses na posição. Não houve distinção de nível de uso da comunicação, idade ou nível socioeconômico-cultural para este estudo.

A versão original foi traduzida para o português brasileiro por duas fonoaudiólogas fluentes na língua estrangeira (tradutora 1 e tradutora 2). Essas traduções foram sobrepostas, resultando na primeira versão em português - VP, mantendo-se a integridade conceitual dos itens. Foi realizada a retro tradução por uma terceira fonoaudióloga, também fluente em inglês, sem acesso à versão original do instrumento e aos objetivos do estudo. 
A tradução e a retro tradução foram comparadas entre si e ao instrumento original. As discrepâncias existentes foram analisadas e discutidas por um comitê composto por cinco fonoaudiólogos especialistas em voz, com proficiência na língua inglesa e conhecimento do vocabulário específico para avaliação da comunicação. As mudanças necessárias foram realizadas por consenso resultando na versão 1 do Comitê - a versão de equivalência semântica e do idioma, intitulada Escala de Reinvestimento Específico da Fala - EREF.

A EREF seguiu o protocolo original, permanecendo com 39 questões e seis alternativas para marcação da frequência de ocorrência da situação descrita em: discordo totalmente (1), discordo (2), discordo ligeiramente (3), concordo ligeiramente (4), concordo (5), concordo totalmente (6). Mantiveram-se ainda, nesse momento, as quatro dimensões subdimensões da escala, sendo elas: 1. Subdimensão da autoconsciência do movimento da fala, 2. Subdimensão da Consciência pública da maneira de falar, 3. Subdimensão da Consciência pública do conteúdo da fala, 4. Subdimensão da Consciência pública da movimentação durante a fala. A pontuação de cada subdimensão do $\operatorname{SSRS}^{(5)}$ é calculada usando o método de pontuação média. A pontuação média composta da EREF é calculada pela soma igualmente ponderada das quatro pontuações médias das subdimensões. Para calcular as médias de cada subdimensão e pontuação média composta, você pode seguir as seguintes etapas:

Q.1-13: Subdimensão da autoconsciência do movimento da fala

Pontuação total: $\div 13$ = Pontuação média da subdimensão:

Q.15-27: Subdimensão da consciência pública da maneira de falar

Pontuação total: $\quad \div 13=$ Pontuação média da subdimensão:

Q.29-33: Subdimensão da consciência pública do conteúdo da fala

Pontuação total: ___ $\div 5=$ Pontuação média da subdimensão:

Q.35-38: Subdimensão da consciência pública da movimentação durante a fala

Pontuação total: ___ _ $\div 4=$ Pontuação média da subdimensão:

Total $=$ Soma das pontuações médias:

É importante ressaltar ainda que existem quatro questões negativas na EREF - uma para cada subdimensão da escala. As questões 14, 28, 34 e 39 não fazem parte da pontuação total da EREF, pois foram desenvolvidas para checar a qualidade de respostas dos indivíduos, incluindo a confiabilidade. Caso o avaliador sinta a necessidade de inclui-las na pontuação, deve lembrar de realizar a pontuação reversa, como descrito no protocolo original ${ }^{(5)}$.

Para a equivalência cultural, a EREF foi aplicada em 74 profissionais da voz falada com o acréscimo da opção "não aplicável" para identificação de questões não compreendidas ou não apropriadas para a população alvo e cultura brasileira. Um espaço para o preenchimento de observações também foi acrescentado ao final da escala, permitindo que os voluntários explicassem suas dificuldades ou dúvidas. Caso os voluntários encontrassem alguma dificuldade para responder a escala, nova tradução e adaptação deveria ser realizada até que não se encontrassem mais barreiras culturais e/ou conceituais.

\section{RESULTADOS}

$\mathrm{Na}$ primeira etapa 61 indivíduos responderam à EREF online. Cinco respostas estavam incompletas, portanto, foram incluídos 56 indivíduos na amostra. Destes, 13 assinalaram "não aplicável" em pelo menos uma das questões da escala. No total 27 questões foram identificadas como não compreendidas ou não apropriadas para a população alvo e cultura brasileira e foram discutidas pelo comitê de Fonoaudiólogos. A questão dois, por exemplo, foi alterada de "Eu estou ciente de como minha boca se move quando eu falo" para "Eu percebo como a minha boca se move quando eu falo", a fim de utilizar uma linguagem de fácil acesso e mais próxima de todos os respondentes. Da mesma forma, optou-se por acrescentar o pronome "eu" em todas as questões, excluindo as frases com sujeitos ocultos para evitar qualquer erro de interpretação. A exemplo disso temos a questão cinco, na qual a frase "Eu penso no movimento dos meus lábios quando falo" foi ajustada para "Eu penso no movimento dos meus lábios quando eu falo".

Além disso, o Comitê de Fonoaudiólogos analisou o que os respondentes haviam escrito no espaço para observações e foi possível concluir que muitos haviam assinalado "não aplicável" não porque as questões não haviam sido compreendidas e sim porque aqueles indivíduos nunca tinham se atentado ao contexto da questão. Ou seja, eles deveriam ter marcado "discordo", pois não concordam com aquela afirmação em vez de "não aplicável". Sendo assim, as instruções para o preenchimento da escala foram revistas para o preenchimento adequado.

A instrução inicial era: "Selecione as opções mais adequadas para indicar o quanto você concorda com cada uma das afirmações: (1) Discordo totalmente, (2) Discordo, (3) Discordo ligeiramente, (4) Concordo ligeiramente, (5) Concordo, (6) Concordo totalmente (Nota: Não há resposta certa ou errada para cada frase). Caso você não compreenda alguma das frases ou entenda que ela não é apropriada à escala, selecione a opção "não aplicável". Ao final das frases, há um espaço para o preenchimento de observações." Após a deliberação do Comitê de Fonoaudiólogos e o entendimento de que as instruções deveriam ser mais claras, houve alteração para: "Selecione as opções mais adequadas para indicar o quanto você concorda com cada uma das afirmações: (1) Discordo totalmente, (2) Discordo, (3) Discordo ligeiramente, (4) Concordo ligeiramente, (5) Concordo, (6) Concordo totalmente (Nota: Não há resposta certa ou errada para cada frase). Caso você não compreenda alguma das frases ou entenda que não faz sentido essa pergunta dentro do questionário, selecione a opção "não aplicável”. Essa marcação só deve ser realizada nesses casos. Se selecionar "não aplicável", solicitamos que você explique suas dificuldades ou dúvidas no espaço dedicado para o preenchimento de observações ao final das frases."

A EREF ajustada - versão 2 do Comitê de Fonoaudiólogos - foi aplicada em 13 novos respondentes, totalizando 69 voluntários incluídos na amostra e não foram identificadas barreiras culturais e/ou conceituais. O mapeamento dos participantes pode ser observado na Figura 1 e a caracterização deles no Quadro 1.

Essa última versão aplicada, resultou então na versão final da EREF, seguindo a equivalência cultural e linguística. Todo o processo de tradução, equivalência semântica e cultural da SSRS para o português brasileiro encontra-se no Quadro 2. 
Quadro 1. Caracterização da amostra de acordo com sexo, idade (em anos) e profissão

\begin{tabular}{|c|c|c|}
\hline Variáveis & $\mathrm{N}$ & $\%$ \\
\hline \multicolumn{3}{|l|}{ Sexo } \\
\hline Feminino & 45 & 65,2 \\
\hline Masculino & 24 & 34,8 \\
\hline \multicolumn{3}{|l|}{ Idade } \\
\hline $18|-| 30$ & 27 & 39,1 \\
\hline $31|-| 45$ & 16 & 23,2 \\
\hline $46|-| 60$ & 20 & 29 \\
\hline $60|-| 86$ & 6 & 8,7 \\
\hline \multicolumn{3}{|l|}{ Profissão } \\
\hline Professor(a) & 9 & 13 \\
\hline Administrador(a) & 6 & 8,7 \\
\hline Empreendedor(a) & 6 & 8,7 \\
\hline Fonoaudiólogo(a) & 5 & 7,2 \\
\hline Publicitário(a) & 5 & 7,2 \\
\hline Engenheiro(a) & 4 & 5,9 \\
\hline Advogado(a) & 3 & 4,4 \\
\hline Aposentado(a) & 3 & 4,4 \\
\hline Empresário(a) & 3 & 4,4 \\
\hline Estudante & 3 & 4,4 \\
\hline Analista & 2 & 2,9 \\
\hline Arquiteto(a) & 2 & 2,9 \\
\hline Consultor(a) & 2 & 2,9 \\
\hline Cozinheiro(a) & 2 & 2,9 \\
\hline Gerente & 2 & 2,9 \\
\hline Jornalista & 2 & 2,9 \\
\hline Médico(a) & 2 & 2,9 \\
\hline Relações Públicas & 2 & 2,9 \\
\hline Terapeuta Ocupacional & 2 & 2,9 \\
\hline Cantor(a) & 1 & 1,4 \\
\hline Dentista & 1 & 1,4 \\
\hline Escritor(a) & 1 & 1,4 \\
\hline Promotor de Justiça & 1 & 1,4 \\
\hline
\end{tabular}

Quadro 2. Processo de tradução e adaptação cultural da escala Speech-Specific Reinvestment Scale - SSRS para o português brasileiro

\begin{tabular}{|c|c|c|c|c|c|c|c|}
\hline Questões & $\begin{array}{l}\text { Versão Original } \\
\text { em inglês }\end{array}$ & \begin{tabular}{|c|} 
Tradução 1 \\
inglês-português
\end{tabular} & $\begin{array}{c}\text { Tradução } 2 \\
\text { inglês-português }\end{array}$ & $\begin{array}{c}\text { Versão } \\
\text { sobreposta (VP) }\end{array}$ & $\begin{array}{l}\text { Retro-tradução } \\
\text { da VP }\end{array}$ & $\begin{array}{l}\text { Versão } 1 \text { do } \\
\text { Comitê }\end{array}$ & $\begin{array}{c}\text { Versão Final do } \\
\text { Comitê }\end{array}$ \\
\hline 1 & $\begin{array}{l}\text { I examine } \\
\text { my mouth } \\
\text { movement when } \\
\text { I speak. }\end{array}$ & $\begin{array}{l}\text { Eu analiso o } \\
\text { movimento da } \\
\text { boca quando } \\
\text { falo. }\end{array}$ & $\begin{array}{c}\text { Eu avalio/ } \\
\text { examino meu } \\
\text { movimento de } \\
\text { boca quando eu } \\
\text { falo. }\end{array}$ & $\begin{array}{l}\text { Eu avalio meu } \\
\text { movimento da } \\
\text { boca quando eu } \\
\text { falo. }\end{array}$ & $\begin{array}{l}\text { When speaking } \\
\text { I monitor } \\
\text { my mouth } \\
\text { movement }\end{array}$ & $\begin{array}{c}\text { Eu avalio } \\
\text { movimento de } \\
\text { boca quando eu } \\
\text { falo. }\end{array}$ & $\begin{array}{c}\text { Eu avalio O } \\
\text { movimento DA } \\
\text { MINHA BOCA } \\
\text { quando eu falo. }\end{array}$ \\
\hline 2 & $\begin{array}{l}\text { I am aware of } \\
\text { the way my } \\
\text { mouth moves } \\
\text { when I speak. }\end{array}$ & $\begin{array}{c}\text { Eu estou ciente } \\
\text { de como minha } \\
\text { boca se move } \\
\text { quando falo. }\end{array}$ & $\begin{array}{l}\text { Estou ciente da } \\
\text { como minha } \\
\text { boca se move } \\
\text { quando falo. }\end{array}$ & $\begin{array}{l}\text { Eu estou ciente } \\
\text { de como minha } \\
\text { boca se move } \\
\text { quando eu falo. }\end{array}$ & $\begin{array}{l}\text { I am aware of } \\
\text { how my mouth } \\
\text { moves when } \\
\text { speaking }\end{array}$ & $\begin{array}{l}\text { Eu estou ciente } \\
\text { de como minha } \\
\text { boca se move } \\
\text { quando eu falo. }\end{array}$ & $\begin{array}{l}\text { Eu PERCEBO } \\
\text { como A minha } \\
\text { boca se move } \\
\text { quando eu falo. }\end{array}$ \\
\hline 3 & $\begin{array}{l}\text { I take time } \\
\text { to reflect on } \\
\text { my mouth } \\
\text { movement after } \\
\text { speaking. }\end{array}$ & $\begin{array}{l}\text { Eu dedico } \\
\text { tempo para } \\
\text { refletir sobre } \\
\text { o movimento } \\
\text { da minha boca } \\
\text { depois de falar. }\end{array}$ & $\begin{array}{l}\text { Eu dedico } \\
\text { tempo para } \\
\text { refletir sobre } \\
\text { o movimento } \\
\text { da minha boca } \\
\text { depois de falar. }\end{array}$ & $\begin{array}{l}\text { Eu dedico } \\
\text { tempo para } \\
\text { refletir sobre } \\
\text { o movimento } \\
\text { da minha boca } \\
\text { depois de falar. }\end{array}$ & $\begin{array}{l}\text { After speaking, } \\
\text { I think about } \\
\text { my mouth } \\
\text { movement }\end{array}$ & $\begin{array}{l}\text { Eu dedico } \\
\text { tempo para } \\
\text { refletir sobre } \\
\text { o movimento } \\
\text { da minha boca } \\
\text { depois de falar. }\end{array}$ & $\begin{array}{c}\text { Eu dedico } \\
\text { tempo para } \\
\text { refletir sobre } \\
\text { o movimento } \\
\text { da minha boca } \\
\text { depois de falar. }\end{array}$ \\
\hline
\end{tabular}


Quadro 2. Continuação...

\begin{tabular}{|c|c|c|c|c|c|c|c|}
\hline Questões & $\begin{array}{l}\text { Versão Original } \\
\text { em inglês }\end{array}$ & $\begin{array}{c}\text { Tradução } 1 \\
\text { inglês-português } \\
\end{array}$ & $\begin{array}{c}\text { Tradução } 2 \\
\text { inglês-português }\end{array}$ & \begin{tabular}{|c} 
Versão \\
sobreposta (VP)
\end{tabular} & $\begin{array}{l}\text { Retro-tradução } \\
\text { da VP }\end{array}$ & $\begin{array}{l}\text { Versão } 1 \text { do } \\
\text { Comitê }\end{array}$ & $\begin{array}{c}\text { Versão Final do } \\
\text { Comitê }\end{array}$ \\
\hline 4 & $\begin{array}{l}\text { I take time to } \\
\text { think about } \\
\text { my mouth } \\
\text { movement } \\
\text { before speaking. }\end{array}$ & $\begin{array}{c}\text { Eu dedico tempo } \\
\text { para pensar } \\
\text { no movimento } \\
\text { da minha boca } \\
\text { antes de falar. }\end{array}$ & $\begin{array}{c}\text { Eu dedico tempo } \\
\text { para pensar } \\
\text { no movimento } \\
\text { da minha boca } \\
\text { antes de falar. }\end{array}$ & $\begin{array}{c}\text { Eu dedico tempo } \\
\text { para pensar } \\
\text { no movimento } \\
\text { da minha boca } \\
\text { antes de falar. }\end{array}$ & $\begin{array}{l}\text { Before speaking, } \\
\text { I think about } \\
\text { my mouth } \\
\text { movement }\end{array}$ & $\begin{array}{c}\text { Eu dedico tempo } \\
\text { para pensar } \\
\text { no movimento } \\
\text { da minha boca } \\
\text { antes de falar. }\end{array}$ & $\begin{array}{c}\text { Eu dedico tempo } \\
\text { para pensar } \\
\text { no movimento } \\
\text { da minha boca } \\
\text { antes de falar. }\end{array}$ \\
\hline 5 & $\begin{array}{l}\text { I think about the } \\
\text { movement of } \\
\text { my lips when I } \\
\text { speak. }\end{array}$ & $\begin{array}{l}\text { Eu penso no } \\
\text { movimento dos } \\
\text { meus lábios } \\
\text { quando falo. }\end{array}$ & $\begin{array}{l}\text { Eu penso no } \\
\text { movimento dos } \\
\text { meus lábios } \\
\text { quando falo. }\end{array}$ & \begin{tabular}{|c|} 
Eu penso no \\
movimento dos \\
meus lábios \\
quando falo. \\
\end{tabular} & $\begin{array}{l}\text { I think about my } \\
\text { lips movements } \\
\text { when speaking }\end{array}$ & $\begin{array}{l}\text { Eu penso no } \\
\text { movimento dos } \\
\text { meus lábios } \\
\text { quando falo. }\end{array}$ & \begin{tabular}{|c|} 
Eu penso no \\
movimento dos \\
meus lábios \\
quando EU falo.
\end{tabular} \\
\hline 6 & $\begin{array}{c}\text { I think about the } \\
\text { movement of my } \\
\text { tongue when I } \\
\text { speak. }\end{array}$ & $\begin{array}{l}\text { Eu penso no } \\
\text { movimento da } \\
\text { minha língua } \\
\text { quando falo. } \\
\end{array}$ & $\begin{array}{c}\text { Eu penso no } \\
\text { movimento da } \\
\text { minha língua } \\
\text { quando falo. }\end{array}$ & $\begin{array}{c}\text { Eu penso no } \\
\text { movimento da } \\
\text { minha língua } \\
\text { quando falo. }\end{array}$ & \begin{tabular}{|c|} 
I think about \\
my toungue \\
movement when \\
speaking \\
\end{tabular} & $\begin{array}{c}\text { Eu penso no } \\
\text { movimento da } \\
\text { minha língua } \\
\text { quando falo. }\end{array}$ & $\begin{array}{c}\text { Eu penso no } \\
\text { movimento da } \\
\text { minha língua } \\
\text { quando EU falo. }\end{array}$ \\
\hline 7 & $\begin{array}{c}\text { I think about the } \\
\text { movement of } \\
\text { my jaw when I } \\
\text { speak. }\end{array}$ & $\begin{array}{c}\text { Eu penso no } \\
\text { movimento da } \\
\text { minha mandíbula } \\
\text { quando falo. }\end{array}$ & $\begin{array}{c}\text { Eu penso no } \\
\text { movimento da } \\
\text { minha mandíbula } \\
\text { quando falo. }\end{array}$ & \begin{tabular}{|c|} 
Eu penso no \\
movimento da \\
minha mandíbula \\
quando falo.
\end{tabular} & $\begin{array}{c}\text { I think about my } \\
\text { jaw movement } \\
\text { when speaking }\end{array}$ & $\begin{array}{c}\text { Eu penso no } \\
\text { movimento da } \\
\text { minha mandíbula } \\
\text { quando falo. }\end{array}$ & $\begin{array}{c}\text { Eu penso no } \\
\text { movimento da } \\
\text { minha mandíbula } \\
\text { quando EU falo. }\end{array}$ \\
\hline 8 & $\begin{array}{l}\text { I think about the } \\
\text { movement of my } \\
\text { larynx when I } \\
\text { speak. }\end{array}$ & $\begin{array}{c}\text { Eu penso no } \\
\text { movimento da } \\
\text { minha laringe } \\
\text { quando falo. }\end{array}$ & $\begin{array}{c}\text { Eu penso no } \\
\text { movimento da } \\
\text { minha laringe } \\
\text { quando eu falo. }\end{array}$ & \begin{tabular}{|c|} 
Eu penso no \\
movimento da \\
minha laringe \\
quando falo. \\
\end{tabular} & $\begin{array}{l}\text { I think about my } \\
\text { larynx movement } \\
\text { when speaking }\end{array}$ & $\begin{array}{l}\text { Eu penso no } \\
\text { movimento da } \\
\text { minha laringe } \\
\text { quando falo. }\end{array}$ & $\begin{array}{c}\text { Eu penso no } \\
\text { movimento da } \\
\text { minha laringe } \\
\text { quando EU falo. }\end{array}$ \\
\hline 9 & $\begin{array}{l}\text { I try to figure out } \\
\text { how my mouth } \\
\text { movement } \\
\text { generates } \\
\text { pronunciation. }\end{array}$ & $\begin{array}{c}\text { Eu tento } \\
\text { descobrir como } \\
\text { o movimento da } \\
\text { minha boca gera } \\
\text { a pronúncia DAS } \\
\text { PALAVRAS. }\end{array}$ & $\begin{array}{c}\text { Eu tento } \\
\text { descobrir como } \\
\text { o movimento da } \\
\text { minha boca gera } \\
\text { a pronúncia. }\end{array}$ & $\begin{array}{c}\text { Eu tento } \\
\text { descobrir como } \\
\text { o movimento da } \\
\text { minha boca gera } \\
\text { a pronúncia das } \\
\text { palavras. } \\
\end{array}$ & $\begin{array}{l}\text { I try figuring } \\
\text { out how my } \\
\text { mouth moments } \\
\text { produce words }\end{array}$ & $\begin{array}{c}\text { Eu tento } \\
\text { descobrir como } \\
\text { o movimento da } \\
\text { minha boca gera } \\
\text { a pronúncia das } \\
\text { palavras. }\end{array}$ & $\begin{array}{c}\text { Eu tento } \\
\text { descobrir como } \\
\text { o movimento da } \\
\text { minha boca gera } \\
\text { a pronúncia das } \\
\text { palavras. }\end{array}$ \\
\hline 10 & $\begin{array}{c}\text { I rethink how } \\
\text { my mouth } \\
\text { movement has } \\
\text { helped me speak } \\
\text { smoothly. }\end{array}$ & \begin{tabular}{|c|} 
Eu repenso \\
em COMO O \\
MOVIMENTO \\
DA MINHA \\
BOCA ME \\
AJUDOU A \\
FALAR SEM \\
DIFICULDADES.
\end{tabular} & $\begin{array}{c}\text { Eu repenso } \\
\text { em como o } \\
\text { movimento da } \\
\text { minha boca me } \\
\text { ajudou a falar } \\
\text { SUAVEMENTE/ } \\
\text { SEM } \\
\text { DIFICULDADES. }\end{array}$ & $\begin{array}{l}\text { Eu repenso } \\
\text { em como o } \\
\text { movimento da } \\
\text { minha boca } \\
\text { me ajudou } \\
\text { a falar sem } \\
\text { dificuldades. }\end{array}$ & $\begin{array}{l}\text { I overthink } \\
\text { how my mouth } \\
\text { movement } \\
\text { helped me } \\
\text { speak easily }\end{array}$ & $\begin{array}{l}\text { Eu repenso } \\
\text { em como o } \\
\text { movimento da } \\
\text { minha boca } \\
\text { me ajudou } \\
\text { a falar sem } \\
\text { dificuldades. }\end{array}$ & $\begin{array}{l}\text { Eu repenso } \\
\text { em como o } \\
\text { movimento da } \\
\text { minha boca } \\
\text { me ajudou } \\
\text { a falar sem } \\
\text { dificuldades. }\end{array}$ \\
\hline 11 & $\begin{array}{c}\text { I think about } \\
\text { how my mouth } \\
\text { movement has } \\
\text { helped me speak } \\
\text { smoothly. }\end{array}$ & $\begin{array}{c}\text { Eu penso } \\
\text { em como o } \\
\text { movimento da } \\
\text { minha boca } \\
\text { me ajudou } \\
\text { a falar sem } \\
\text { dificuldades. }\end{array}$ & $\begin{array}{l}\text { Penso em como } \\
\text { o movimento da } \\
\text { minha boca me } \\
\text { ajudou a falar } \\
\text { SUAVEMENTE/ } \\
\text { sem } \\
\text { dificuldades. }\end{array}$ & $\begin{array}{c}\text { Eu penso } \\
\text { em como o } \\
\text { movimento da } \\
\text { minha boca } \\
\text { me ajudou } \\
\text { a falar sem } \\
\text { dificuldades. }\end{array}$ & $\begin{array}{l}\text { I think how } \\
\text { my mouth } \\
\text { movement } \\
\text { helped me } \\
\text { speak easily }\end{array}$ & $\begin{array}{l}\text { Eu penso } \\
\text { em como o } \\
\text { movimento da } \\
\text { minha boca } \\
\text { me ajudou } \\
\text { a falar sem } \\
\text { dificuldades. }\end{array}$ & $\begin{array}{l}\text { Eu penso } \\
\text { em como o } \\
\text { movimento da } \\
\text { minha boca } \\
\text { me ajudou } \\
\text { a falar sem } \\
\text { dificuldades. }\end{array}$ \\
\hline 12 & $\begin{array}{l}\text { I try to } \\
\text { understand } \\
\text { how my } \\
\text { speech arises } \\
\text { from mouth } \\
\text { movement. }\end{array}$ & $\begin{array}{c}\text { Eu tento } \\
\text { entender como } \\
\text { minha fala surge } \\
\text { do movimento } \\
\text { DA MINHA } \\
\text { boca. }\end{array}$ & $\begin{array}{c}\text { Eu tento } \\
\text { entender como } \\
\text { minha fala surge } \\
\text { do movimento } \\
\text { da boca. }\end{array}$ & $\begin{array}{l}\text { Eu tento } \\
\text { entender como } \\
\text { minha fala surge } \\
\text { do movimento } \\
\text { da minha boca. }\end{array}$ & $\begin{array}{l}\text { I try to } \\
\text { understand } \\
\text { how my speech } \\
\text { is produced } \\
\text { from my mouth } \\
\text { movement }\end{array}$ & $\begin{array}{l}\text { Eu tento } \\
\text { entender como } \\
\text { minha fala surge } \\
\text { do movimento } \\
\text { da minha boca. }\end{array}$ & $\begin{array}{l}\text { Eu tento } \\
\text { entender como } \\
\text { minha fala surge } \\
\text { do movimento } \\
\text { da minha boca. }\end{array}$ \\
\hline 13 & $\begin{array}{l}\text { I am aware of } \\
\text { how my mouth } \\
\text { moves for what I } \\
\text { want to speak. }\end{array}$ & $\begin{array}{l}\text { EU estou ciente } \\
\text { de como minha } \\
\text { boca se move } \\
\text { para o que eu } \\
\text { quero falar. } \\
\end{array}$ & $\begin{array}{l}\text { Estou ciente de } \\
\text { como minha } \\
\text { boca se move } \\
\text { para o que eu } \\
\text { quero falar. } \\
\end{array}$ & $\begin{array}{c}\text { Eu estou ciente } \\
\text { de como minha } \\
\text { boca se move } \\
\text { para o que eu } \\
\text { quero falar. } \\
\end{array}$ & $\begin{array}{l}\text { I am aware of } \\
\text { how my mouth } \\
\text { moves when } \\
\text { speaking what I } \\
\text { want } \\
\end{array}$ & $\begin{array}{c}\text { Eu estou ciente } \\
\text { de como minha } \\
\text { boca se move } \\
\text { para o que eu } \\
\text { quero falar. } \\
\end{array}$ & $\begin{array}{c}\text { Eu PERCEBO } \\
\text { como minha } \\
\text { boca se move } \\
\text { para o que eu } \\
\text { quero falar. } \\
\end{array}$ \\
\hline 14 & $\begin{array}{l}\text { I do not try } \\
\text { to figure out } \\
\text { how my mouth } \\
\text { movement } \\
\text { generates } \\
\text { pronunciation. }\end{array}$ & $\begin{array}{c}\text { EU não tento } \\
\text { descobrir como } \\
\text { o movimento da } \\
\text { minha boca gera } \\
\text { A PRONÚNCIA } \\
\text { DAS } \\
\text { PALAVRAS. }\end{array}$ & $\begin{array}{c}\text { Não tento } \\
\text { descobrir como } \\
\text { o movimento da } \\
\text { minha boca gera } \\
\text { pronúncia. }\end{array}$ & $\begin{array}{c}\text { Eu não tento } \\
\text { descobrir como } \\
\text { o movimento da } \\
\text { minha boca gera } \\
\text { a pronúncia das } \\
\text { palavras. }\end{array}$ & $\begin{array}{l}\text { I do not try } \\
\text { figuring out } \\
\text { how my mouth } \\
\text { moments } \\
\text { produce words }\end{array}$ & $\begin{array}{c}\text { Eu não tento } \\
\text { descobrir como } \\
\text { o movimento da } \\
\text { minha boca gera } \\
\text { a pronúncia das } \\
\text { palavras. }\end{array}$ & $\begin{array}{c}\text { Eu não tento } \\
\text { descobrir como } \\
\text { o movimento da } \\
\text { minha boca gera } \\
\text { a pronúncia das } \\
\text { palavras. }\end{array}$ \\
\hline
\end{tabular}

Fonte: elaborada pelos autores 
Quadro 2. Continuação...

\begin{tabular}{|c|c|c|c|c|c|c|c|}
\hline Questões & $\begin{array}{l}\text { Versão Original } \\
\text { em inglês }\end{array}$ & $\begin{array}{c}\text { Tradução } 1 \\
\text { inglês-português }\end{array}$ & $\begin{array}{c}\text { Tradução } 2 \\
\text { inglês-português }\end{array}$ & $\begin{array}{c}\text { Versão } \\
\text { sobreposta (VP) }\end{array}$ & $\begin{array}{l}\text { Retro-tradução } \\
\text { da VP }\end{array}$ & $\begin{array}{l}\text { Versão } 1 \text { do } \\
\text { Comitê }\end{array}$ & $\begin{array}{c}\text { Versão Final do } \\
\text { Comitê }\end{array}$ \\
\hline 15 & $\begin{array}{l}\text { I care about } \\
\text { the voice being } \\
\text { used to present } \\
\text { myself to others. }\end{array}$ & $\begin{array}{c}\text { Eu me preocupo } \\
\text { com a minha } \\
\text { voz QUANDO } \\
\text { EU ME } \\
\text { APRESENTO } \\
\text { aos outros. }\end{array}$ & $\begin{array}{c}\text { Eu me preocupo } \\
\text { COM A VOZ } \\
\text { SENDO USADA } \\
\text { para me } \\
\text { apresentar aos } \\
\text { outros. }\end{array}$ & $\begin{array}{c}\text { Eu me preocupo } \\
\text { com a voz que } \\
\text { eu uso para para } \\
\text { me apresentar } \\
\text { aos outros. }\end{array}$ & $\begin{array}{c}\text { My voice } \\
\text { concerns me } \\
\text { when I introduce } \\
\text { myself }\end{array}$ & $\begin{array}{l}\text { Eu me preocupo } \\
\text { com a voz que } \\
\text { eu uso para para } \\
\text { me apresentar } \\
\text { aos outros. }\end{array}$ & $\begin{array}{c}\text { Eu me preocupo } \\
\text { com a voz que } \\
\text { eu uso para me } \\
\text { apresentar aos } \\
\text { outros. }\end{array}$ \\
\hline 16 & $\begin{array}{l}\text { Before I talk to } \\
\text { others, I think } \\
\text { about how my } \\
\text { pronunciation is. }\end{array}$ & $\begin{array}{l}\text { Antes de falar } \\
\text { com outras } \\
\text { pessoas, EU } \\
\text { penso em como } \\
\text { está minha } \\
\text { pronúncia. }\end{array}$ & $\begin{array}{l}\text { Antes de falar } \\
\text { com outras } \\
\text { pessoas, penso } \\
\text { em como } \\
\text { está a minha } \\
\text { pronúncia. } \\
\end{array}$ & $\begin{array}{l}\text { Antes de falar } \\
\text { com outras } \\
\text { pessoas, eu } \\
\text { penso em como } \\
\text { está minha } \\
\text { pronúncia. } \\
\end{array}$ & $\begin{array}{l}\text { Before speaking } \\
\text { with other } \\
\text { people I think } \\
\text { about my } \\
\text { pronunciation }\end{array}$ & $\begin{array}{l}\text { Antes de falar } \\
\text { com outras } \\
\text { pessoas, eu } \\
\text { penso em como } \\
\text { está minha } \\
\text { pronúncia. }\end{array}$ & $\begin{array}{l}\text { Antes de falar } \\
\text { com outras } \\
\text { pessoas, eu } \\
\text { penso como } \\
\text { está minha } \\
\text { pronúncia. }\end{array}$ \\
\hline 17 & $\begin{array}{l}\text { I care about my } \\
\text { pronunciation } \\
\text { when I am } \\
\text { invited to } \\
\text { express my } \\
\text { views. }\end{array}$ & $\begin{array}{l}\text { Eu me preocupo } \\
\text { com a minha } \\
\text { pronúncia } \\
\text { quando sou } \\
\text { convidado a } \\
\text { expressar meus } \\
\text { pontos de vista. }\end{array}$ & $\begin{array}{l}\text { Eu me preocupo } \\
\text { com a minha } \\
\text { pronúncia } \\
\text { quando sou } \\
\text { convidado a } \\
\text { expressar meus } \\
\text { pontos de vista. }\end{array}$ & $\begin{array}{l}\text { Eu me preocupo } \\
\text { com a minha } \\
\text { pronúncia } \\
\text { quando sou } \\
\text { convidado a dar } \\
\text { minhas opiniões. }\end{array}$ & $\begin{array}{l}\text { My } \\
\text { pronunciation } \\
\text { concerns me } \\
\text { when I am } \\
\text { invited to give } \\
\text { opinions }\end{array}$ & $\begin{array}{l}\text { Eu me preocupo } \\
\text { com a minha } \\
\text { pronúncia } \\
\text { quando sou } \\
\text { convidado a dar } \\
\text { minhas opiniões. }\end{array}$ & $\begin{array}{l}\text { Eu me preocupo } \\
\text { com a minha } \\
\text { pronúncia } \\
\text { quando EU sou } \\
\text { convidado a dar } \\
\text { minhas opiniões. }\end{array}$ \\
\hline 18 & $\begin{array}{l}\text { I am concerned } \\
\text { about what } \\
\text { other people } \\
\text { think about } \\
\text { my volume of } \\
\text { speech. }\end{array}$ & $\begin{array}{c}\text { Eu fico } \\
\text { preocupado com } \\
\text { o que as outras } \\
\text { pessoas pensam } \\
\text { sobre o volume } \\
\text { DE MINHA VOZ. }\end{array}$ & $\begin{array}{c}\text { Estou } \\
\text { preocupado } \\
\text { com o que as } \\
\text { outras pessoas } \\
\text { pensam sobre o } \\
\text { meu volume DE } \\
\text { FALA. }\end{array}$ & \begin{tabular}{|c|} 
Estou \\
preocupado com \\
o que as outras \\
pessoas pensam \\
sobre o volume \\
da minha fala.
\end{tabular} & $\begin{array}{c}\text { I am concern } \\
\text { of what people } \\
\text { think about my } \\
\text { speech loudness }\end{array}$ & \begin{tabular}{|} 
Estou \\
preocupado com \\
o que as outras \\
pessoas pensam \\
sobre o volume \\
da minha fala.
\end{tabular} & $\begin{array}{c}\text { EU FICO } \\
\text { PREOCUPADO(A) } \\
\text { com o que as } \\
\text { outras pessoas } \\
\text { pensam sobre o } \\
\text { volume da minha } \\
\text { fala. }\end{array}$ \\
\hline 19 & $\begin{array}{l}\text { I care about } \\
\text { my volume of } \\
\text { speech when I } \\
\text { am presenting } \\
\text { myself to others. }\end{array}$ & $\begin{array}{c}\text { Eu me preocupo } \\
\text { com o VOLUME } \\
\text { DE MINHA VOZ } \\
\text { quando eu ME } \\
\text { APRESENTO a } \\
\text { outras pessoas. }\end{array}$ & $\begin{array}{l}\text { Eu me preocupo } \\
\text { com o MEU } \\
\text { VOLUME DE } \\
\text { FALA quando } \\
\text { ESTOU ME } \\
\text { APRESENTANDO } \\
\text { para os outros. }\end{array}$ & $\begin{array}{c}\text { Eu me preocupo } \\
\text { com o volume } \\
\text { da minha } \\
\text { fala quando } \\
\text { estou me } \\
\text { apresentando a } \\
\text { outras pessoas. }\end{array}$ & $\begin{array}{c}\text { My speech } \\
\text { loudness } \\
\text { concerns me } \\
\text { when I introduce } \\
\text { myself }\end{array}$ & $\begin{array}{l}\text { Eu me preocupo } \\
\text { com o volume } \\
\text { da minha } \\
\text { fala quando } \\
\text { estou me } \\
\text { apresentando a } \\
\text { outras pessoas. }\end{array}$ & $\begin{array}{c}\text { Eu me preocupo } \\
\text { com o volume } \\
\text { da minha } \\
\text { fala quando } \\
\text { EU estou me } \\
\text { apresentando } \\
\text { PARA outras } \\
\text { pessoas. }\end{array}$ \\
\hline 20 & $\begin{array}{l}\text { I worry about } \\
\text { making a good } \\
\text { impression with } \\
\text { my volume of } \\
\text { speech. }\end{array}$ & $\begin{array}{l}\text { Eu me preocupo } \\
\text { em causar uma } \\
\text { boa impressão } \\
\text { com o VOLUME } \\
\text { DE MINHA VOZ. }\end{array}$ & $\begin{array}{c}\text { Eu me preocupo } \\
\text { em causar uma } \\
\text { boa impressão } \\
\text { no meu } \\
\text { voLUME DE } \\
\text { FALA. }\end{array}$ & $\begin{array}{c}\text { Eu me preocupo } \\
\text { em causar uma } \\
\text { boa impressão } \\
\text { no volume da } \\
\text { minha fala. }\end{array}$ & $\begin{array}{l}\text { I am concern } \\
\text { with making a } \\
\text { good impression } \\
\text { on my speech } \\
\text { loudness }\end{array}$ & $\begin{array}{c}\text { Eu me preocupo } \\
\text { em causar uma } \\
\text { boa impressão } \\
\text { no volume da } \\
\text { minha fala. }\end{array}$ & $\begin{array}{c}\text { Eu me preocupo } \\
\text { em causar uma } \\
\text { boa impressão } \\
\text { no volume da } \\
\text { minha fala. }\end{array}$ \\
\hline 21 & $\begin{array}{l}\text { Before I talk } \\
\text { to others, I } \\
\text { think about } \\
\text { my volume of } \\
\text { speech. }\end{array}$ & $\begin{array}{l}\text { Antes de falar } \\
\text { com outras } \\
\text { pessoas, eu } \\
\text { penso no } \\
\text { VOLUME DA } \\
\text { MINHA VOZ. }\end{array}$ & $\begin{array}{l}\text { Antes de falar } \\
\text { com outras } \\
\text { pessoas, } \\
\text { penso no meu } \\
\text { VOLUME DE } \\
\text { FALA. }\end{array}$ & \begin{tabular}{|c|} 
Antes de falar \\
com outras \\
pessoas, eu \\
penso no \\
volume da minha \\
fala. \\
\end{tabular} & $\begin{array}{l}\text { Before speaking } \\
\text { with other } \\
\text { people I think } \\
\text { about my } \\
\text { speech loudness }\end{array}$ & $\begin{array}{c}\text { Antes de falar } \\
\text { com outras } \\
\text { pessoas, eu } \\
\text { penso no } \\
\text { volume da minha } \\
\text { fala. } \\
\end{array}$ & $\begin{array}{c}\text { Antes de falar } \\
\text { com outras } \\
\text { pessoas, eu } \\
\text { penso no } \\
\text { volume da minha } \\
\text { fala. }\end{array}$ \\
\hline 22 & $\begin{array}{c}\text { I care about } \\
\text { my volume of } \\
\text { speech when } \\
\text { I am invited to } \\
\text { express my view. }\end{array}$ & $\begin{array}{c}\text { Eu me preocupo } \\
\text { com o VOLUME } \\
\text { DE MINHA VOZ } \\
\text { quando sou } \\
\text { convidado a } \\
\text { expressar minha } \\
\text { opinião. }\end{array}$ & $\begin{array}{c}\text { Eu me preocupo } \\
\text { com meu } \\
\text { VOLUME DE } \\
\text { FALA quando } \\
\text { sou convidado a } \\
\text { expressar minha } \\
\text { opinião. }\end{array}$ & $\begin{array}{l}\text { Eu me preocupo } \\
\text { com o volume } \\
\text { da minha fala } \\
\text { quando sou } \\
\text { convidado a dar } \\
\text { minha opinião. }\end{array}$ & $\begin{array}{c}\text { I am concern } \\
\text { with my speech } \\
\text { loudness when I } \\
\text { am asked to give } \\
\text { my opinion }\end{array}$ & $\begin{array}{l}\text { Eu me preocupo } \\
\text { com o volume } \\
\text { da minha fala } \\
\text { quando sou } \\
\text { convidado a dar } \\
\text { minha opinião. }\end{array}$ & $\begin{array}{l}\text { Eu me preocupo } \\
\text { com o volume } \\
\text { da minha fala } \\
\text { quando EU sou } \\
\text { convidado(a) } \\
\text { a dar minha } \\
\text { opinião. }\end{array}$ \\
\hline 23 & $\begin{array}{l}\text { I am concerned } \\
\text { about what } \\
\text { other people } \\
\text { think about my } \\
\text { speech rate. }\end{array}$ & $\begin{array}{c}\text { EU FICO } \\
\text { PREOCUPADO } \\
\text { com o que as } \\
\text { outras pessoas } \\
\text { pensam } \\
\text { sobre a minha } \\
\text { velocidade de } \\
\text { fala. }\end{array}$ & $\begin{array}{c}\text { ESTOU } \\
\text { PREOCUPADO } \\
\text { com o que as } \\
\text { outras pessoas } \\
\text { pensam } \\
\text { sobre a minha } \\
\text { velocidade de } \\
\text { fala. }\end{array}$ & $\begin{array}{c}\text { Eu fico } \\
\text { preocupado } \\
\text { com o que as } \\
\text { outras pessoas } \\
\text { pensam sobre } \\
\text { a velocidade da } \\
\text { minha fala. }\end{array}$ & $\begin{array}{l}\text { I am concern } \\
\text { of what people } \\
\text { think about my } \\
\text { speech rate }\end{array}$ & $\begin{array}{c}\text { Eu fico } \\
\text { preocupado } \\
\text { com o que as } \\
\text { outras pessoas } \\
\text { pensam sobre } \\
\text { a velocidade da } \\
\text { minha fala. }\end{array}$ & $\begin{array}{c}\text { Eu fico } \\
\text { preocupado(a) } \\
\text { com o que as } \\
\text { outras pessoas } \\
\text { pensam sobre } \\
\text { a velocidade da } \\
\text { minha fala. }\end{array}$ \\
\hline
\end{tabular}


Quadro 2. Continuação...

\begin{tabular}{|c|c|c|c|c|c|c|c|}
\hline Questões & $\begin{array}{l}\text { Versão Original } \\
\text { em inglês }\end{array}$ & $\begin{array}{c}\text { Tradução } 1 \\
\text { inglês-português }\end{array}$ & $\begin{array}{c}\text { Tradução } 2 \\
\text { inglês-português }\end{array}$ & $\begin{array}{c}\text { Versão } \\
\text { sobreposta (VP) }\end{array}$ & $\begin{array}{l}\text { Retro-tradução } \\
\text { da VP }\end{array}$ & $\begin{array}{l}\text { Versão } 1 \text { do } \\
\text { Comitê }\end{array}$ & $\begin{array}{c}\text { Versão Final do } \\
\text { Comitê }\end{array}$ \\
\hline 24 & $\begin{array}{l}\text { I care about } \\
\text { my speech } \\
\text { rate when I } \\
\text { am presenting } \\
\text { myself to others. }\end{array}$ & $\begin{array}{l}\text { Eu me } \\
\text { preocupo com } \\
\text { a velocidade } \\
\text { de minha } \\
\text { fala quando } \\
\text { estou me } \\
\text { apresentando a } \\
\text { outras pessoas. }\end{array}$ & $\begin{array}{c}\text { Eu me preocupo } \\
\text { com a minha } \\
\text { velocidade de } \\
\text { fala quando } \\
\text { estou me } \\
\text { apresentando } \\
\text { para outras } \\
\text { pessoas. }\end{array}$ & $\begin{array}{l}\text { Eu me } \\
\text { preocupo com } \\
\text { a velocidade } \\
\text { da minha } \\
\text { fala quando } \\
\text { estou me } \\
\text { apresentando a } \\
\text { outras pessoas. }\end{array}$ & $\begin{array}{c}\text { My speech rate } \\
\text { concerns me } \\
\text { when I introduce } \\
\text { myself }\end{array}$ & $\begin{array}{l}\text { Eu me } \\
\text { preocupo com } \\
\text { a velocidade } \\
\text { da minha } \\
\text { fala quando } \\
\text { estou me } \\
\text { apresentando a } \\
\text { outras pessoas. }\end{array}$ & $\begin{array}{c}\text { Eu me } \\
\text { preocupo com } \\
\text { a velocidade } \\
\text { da minha } \\
\text { fala quando } \\
\text { EU estou me } \\
\text { apresentando } \\
\text { PARA outras } \\
\text { pessoas. } \\
\end{array}$ \\
\hline 25 & $\begin{array}{l}\text { I worry about } \\
\text { making a good } \\
\text { impression with } \\
\text { my speech rate. }\end{array}$ & $\begin{array}{c}\text { Eu me preocupo } \\
\text { em causar } \\
\text { uma boa } \\
\text { impressão com } \\
\text { a VELOCIDADE } \\
\text { DE MINHA } \\
\text { FALA. }\end{array}$ & $\begin{array}{c}\text { Eu me preocupo } \\
\text { em causar uma } \\
\text { boa impressão } \\
\text { com A MINHA } \\
\text { VELOCIDADE } \\
\text { DE FALA. }\end{array}$ & $\begin{array}{l}\text { Eu me preocupo } \\
\text { em causar } \\
\text { uma boa } \\
\text { impressão com } \\
\text { a velocidade da } \\
\text { minha fala. }\end{array}$ & $\begin{array}{l}\text { I am concern } \\
\text { with making a } \\
\text { good impression } \\
\text { on my speech } \\
\text { rate }\end{array}$ & $\begin{array}{l}\text { Eu me preocupo } \\
\text { em causar } \\
\text { uma boa } \\
\text { impressão com } \\
\text { a velocidade da } \\
\text { minha fala. }\end{array}$ & $\begin{array}{l}\text { Eu me preocupo } \\
\text { em causar } \\
\text { uma boa } \\
\text { impressão com } \\
\text { a velocidade da } \\
\text { minha fala. }\end{array}$ \\
\hline 26 & $\begin{array}{l}\text { Before I talk } \\
\text { to others, I } \\
\text { think about my } \\
\text { speech rate. }\end{array}$ & $\begin{array}{l}\text { Antes de falar } \\
\text { com outras } \\
\text { pessoas, eu } \\
\text { penso na } \\
\text { VELOCIDADE } \\
\text { DE MINHA } \\
\text { FALA. }\end{array}$ & $\begin{array}{l}\text { Antes de falar } \\
\text { com outras } \\
\text { pessoas, } \\
\text { eu penso } \\
\text { NA MINHA } \\
\text { VELOCIDADE } \\
\text { DE FALA. }\end{array}$ & $\begin{array}{l}\text { Antes de falar } \\
\text { com outras } \\
\text { pessoas, eu } \\
\text { penso na } \\
\text { velocidade da } \\
\text { minha fala. }\end{array}$ & $\begin{array}{l}\text { Before speaking } \\
\text { with other } \\
\text { people I think } \\
\text { about my } \\
\text { speech rate }\end{array}$ & $\begin{array}{l}\text { Antes de falar } \\
\text { com outras } \\
\text { pessoas, eu } \\
\text { penso na } \\
\text { velocidade da } \\
\text { minha fala. }\end{array}$ & $\begin{array}{l}\text { Antes de falar } \\
\text { com outras } \\
\text { pessoas, eu } \\
\text { penso na } \\
\text { velocidade da } \\
\text { minha fala. }\end{array}$ \\
\hline 27 & $\begin{array}{l}\text { I care about } \\
\text { my speech } \\
\text { rate when I } \\
\text { am invited to } \\
\text { express my view. }\end{array}$ & $\begin{array}{c}\text { Eu me } \\
\text { preocupo com } \\
\text { a VELOCIDADE } \\
\text { DA MINHA } \\
\text { FALA quando } \\
\text { sou chamado a } \\
\text { expressar minha } \\
\text { opinião. }\end{array}$ & $\begin{array}{c}\text { Eu me preocupo } \\
\text { com a MINHA } \\
\text { VELOCIDADE } \\
\text { DE FALA } \\
\text { quando sou } \\
\text { convidado a } \\
\text { expressar minha } \\
\text { opinião. }\end{array}$ & $\begin{array}{c}\text { Eu me } \\
\text { preocupo com } \\
\text { a velocidade } \\
\text { da minha fala } \\
\text { quando sou } \\
\text { convidado a dar } \\
\text { minha opinião. }\end{array}$ & $\begin{array}{l}\text { I am concern } \\
\text { with my speech } \\
\text { rate when I am } \\
\text { asked to give my } \\
\text { opinion }\end{array}$ & $\begin{array}{c}\text { Eu me } \\
\text { preocupo com } \\
\text { a velocidade } \\
\text { da minha fala } \\
\text { quando sou } \\
\text { convidado a dar } \\
\text { minha opinião. }\end{array}$ & $\begin{array}{c}\text { Eu me } \\
\text { preocupo com } \\
\text { a velocidade } \\
\text { da minha fala } \\
\text { quando EU sou } \\
\text { convidado a dar } \\
\text { minha opinião. }\end{array}$ \\
\hline 28 & $\begin{array}{l}\text { Before I talk } \\
\text { to others, I } \\
\text { do not think } \\
\text { about how my } \\
\text { pronunciation is. }\end{array}$ & $\begin{array}{l}\text { Antes de falar } \\
\text { com outras } \\
\text { pessoas, eu não } \\
\text { penso em como } \\
\text { está minha } \\
\text { pronúncia DAS } \\
\text { PALAVRAS. }\end{array}$ & $\begin{array}{l}\text { Antes de falar } \\
\text { com outras } \\
\text { pessoas, não } \\
\text { penso em como } \\
\text { está minha } \\
\text { pronúncia. }\end{array}$ & $\begin{array}{l}\text { Antes de falar } \\
\text { com outras } \\
\text { pessoas, eu não } \\
\text { penso em como } \\
\text { está minha } \\
\text { pronúncia das } \\
\text { palavras. }\end{array}$ & $\begin{array}{l}\text { Before speaking } \\
\text { with other } \\
\text { people I do not } \\
\text { think about my } \\
\text { pronunciation }\end{array}$ & $\begin{array}{l}\text { Antes de falar } \\
\text { com outras } \\
\text { pessoas, eu não } \\
\text { penso em como } \\
\text { está minha } \\
\text { pronúncia das } \\
\text { palavras. } \\
\end{array}$ & $\begin{array}{l}\text { Antes de falar } \\
\text { com outras } \\
\text { pessoas, eu não } \\
\text { penso em como } \\
\text { está minha } \\
\text { pronúncia das } \\
\text { palavras. } \\
\end{array}$ \\
\hline 29 & $\begin{array}{l}\text { I am concerned } \\
\text { about what } \\
\text { other people } \\
\text { think about my } \\
\text { speech content. }\end{array}$ & $\begin{array}{c}\text { EU FICO } \\
\text { PREOCUPADO } \\
\text { com o que as } \\
\text { outras pessoas } \\
\text { pensam SOBRE } \\
\text { O CONTEÚDO } \\
\text { DE MINHA } \\
\text { FALA. }\end{array}$ & $\begin{array}{c}\text { ESTOU } \\
\text { PREOCUPADO } \\
\text { com o que as } \\
\text { outras pessoas } \\
\text { pensam } \\
\text { SOBRE O MEU } \\
\text { CONTEÚDO DE } \\
\text { FALA. }\end{array}$ & $\begin{array}{c}\text { Eu fico } \\
\text { preocupado } \\
\text { com o que as } \\
\text { outras pessoas } \\
\text { pensam sobre } \\
\text { o conteúdo da } \\
\text { minha fala. }\end{array}$ & $\begin{array}{l}\text { The content } \\
\text { of my speech } \\
\text { concerns me } \\
\text { when talking } \\
\text { with other } \\
\text { people }\end{array}$ & $\begin{array}{c}\text { Eu fico } \\
\text { preocupado } \\
\text { com o que as } \\
\text { outras pessoas } \\
\text { pensam sobre } \\
\text { o conteúdo da } \\
\text { minha fala. }\end{array}$ & $\begin{array}{c}\text { Eu fico } \\
\text { preocupado } \\
\text { com o que as } \\
\text { outras pessoas } \\
\text { pensam sobre } \\
\text { o conteúdo da } \\
\text { minha fala. }\end{array}$ \\
\hline 30 & $\begin{array}{l}\text { I care about } \\
\text { how the content } \\
\text { is organized } \\
\text { when presenting } \\
\text { myself to others. }\end{array}$ & $\begin{array}{c}\text { Eu me } \\
\text { preocupo com } \\
\text { a organização } \\
\text { do CONTEÚDo } \\
\text { DO QUE VOU } \\
\text { FALAR ao me } \\
\text { apresentar a } \\
\text { outras pessoas. }\end{array}$ & $\begin{array}{c}\text { Eu me } \\
\text { preocupo com } \\
\text { a organização } \\
\text { do conteúdo ao } \\
\text { me apresentar a } \\
\text { outras pessoas. }\end{array}$ & $\begin{array}{c}\text { Eu me } \\
\text { preocupo com } \\
\text { a organização } \\
\text { do conteúdo do } \\
\text { que vou falar ao } \\
\text { me apresentar a } \\
\text { outras pessoas. }\end{array}$ & $\begin{array}{c}\text { The content } \\
\text { organization } \\
\text { concerns me } \\
\text { when I introduce } \\
\text { myself }\end{array}$ & $\begin{array}{c}\text { Eu me } \\
\text { preocupo com } \\
\text { a organização } \\
\text { do conteúdo do } \\
\text { que vou falar ao } \\
\text { me apresentar a } \\
\text { outras pessoas. }\end{array}$ & $\begin{array}{c}\text { Eu me } \\
\text { preocupo com a } \\
\text { organização do } \\
\text { conteúdo do que } \\
\text { EU vou falar ao } \\
\text { me apresentar } \\
\text { PARA outras } \\
\text { pessoas. }\end{array}$ \\
\hline 31 & $\begin{array}{l}\text { I worry about } \\
\text { making a good } \\
\text { impression with } \\
\text { my speech } \\
\text { content. }\end{array}$ & $\begin{array}{c}\text { Eu me preocupo } \\
\text { em causar uma } \\
\text { boa impressão } \\
\text { com o } \\
\text { CONTEÚDO DE } \\
\text { MINHA FALA. }\end{array}$ & $\begin{array}{c}\text { Eu me preocupo } \\
\text { em causar uma } \\
\text { boa impressão } \\
\text { com o MEU } \\
\text { CONTEÚDO DE } \\
\text { FALA. }\end{array}$ & $\begin{array}{l}\text { Eu me preocupo } \\
\text { em causar uma } \\
\text { boa impressão } \\
\text { com o conteúdo } \\
\text { da minha fala. }\end{array}$ & $\begin{array}{c}\text { I am concern } \\
\text { with making a } \\
\text { good impression } \\
\text { with my speech } \\
\text { content }\end{array}$ & $\begin{array}{c}\text { Eu me preocupo } \\
\text { em causar uma } \\
\text { boa impressão } \\
\text { com o conteúdo } \\
\text { da minha fala. }\end{array}$ & $\begin{array}{l}\text { Eu me preocupo } \\
\text { em causar uma } \\
\text { boa impressão } \\
\text { com o conteúdo } \\
\text { da minha fala. }\end{array}$ \\
\hline
\end{tabular}

\footnotetext{
Fonte: elaborada pelos autores
} 
Quadro 2. Continuação...

\begin{tabular}{|c|c|c|c|c|c|c|c|}
\hline Questões & $\begin{array}{c}\text { Versão Original } \\
\text { em inglês }\end{array}$ & $\begin{array}{c}\text { Tradução } 1 \\
\text { gglês-português }\end{array}$ & \begin{tabular}{|c|c} 
Tradução 2 \\
inglês-português
\end{tabular} & $\begin{array}{c}\text { Versão } \\
\text { sobreposta (VP) }\end{array}$ & $\begin{array}{c}\text { Retro-tradução } \\
\text { da VP }\end{array}$ & $\begin{array}{l}\text { Versão } 1 \text { do } \\
\text { Comitê }\end{array}$ & $\begin{array}{c}\text { Versão Final do } \\
\text { Comitê }\end{array}$ \\
\hline 32 & $\begin{array}{l}\text { Before I talk to } \\
\text { others, I think } \\
\text { about how the } \\
\text { content of my } \\
\text { speech is. }\end{array}$ & $\begin{array}{l}\text { Antes de falar } \\
\text { com outras } \\
\text { pessoas, eu } \\
\text { penso no } \\
\text { CONTEÚDo } \\
\text { DO QUE VOU } \\
\text { FALAR. }\end{array}$ & $\begin{array}{l}\text { Antes de falar } \\
\text { com outras } \\
\text { pessoas, } \\
\text { penso EM } \\
\text { COMO ESTÁ } \\
\text { O CONTEÚDO } \\
\text { DO MEU } \\
\text { DISCURSO. } \\
\end{array}$ & $\begin{array}{l}\text { Antes de falar } \\
\text { com outras } \\
\text { pessoas, eu } \\
\text { penso no } \\
\text { conteúdo do que } \\
\text { eu vou falar. }\end{array}$ & $\begin{array}{c}\text { Before speaking } \\
\text { with other people } \\
\text { I think about my } \\
\text { speech content }\end{array}$ & $\begin{array}{l}\text { Antes de falar } \\
\text { com outras } \\
\text { pessoas, eu } \\
\text { penso no } \\
\text { conteúdo do que } \\
\text { eu vou falar. }\end{array}$ & $\begin{array}{l}\text { Antes de falar } \\
\text { com outras } \\
\text { pessoas, eu } \\
\text { penso no } \\
\text { conteúdo do que } \\
\text { eu vou falar. }\end{array}$ \\
\hline 33 & $\begin{array}{l}\text { I care about } \\
\text { my speech } \\
\text { content when } \\
\text { I am invited } \\
\text { to express my } \\
\text { views. }\end{array}$ & $\begin{array}{c}\text { Eu me } \\
\text { preocupo com } \\
\text { o CONTEÚDO } \\
\text { DO QUE } \\
\text { VOU FALAR } \\
\text { QUANDO SOU } \\
\text { CONVIDADO A } \\
\text { DAR MINHAS } \\
\text { OPINIÕES. }\end{array}$ & $\begin{array}{c}\text { Eu me } \\
\text { preocupo com o } \\
\text { CONTEÚDO DA } \\
\text { MINHA FALA } \\
\text { QUANDO SOU } \\
\text { CONVIDADO } \\
\text { A EXPRESSAR } \\
\text { MINHAS } \\
\text { OPINIÕES. }\end{array}$ & $\begin{array}{l}\text { Eu me preocupo } \\
\text { com o conteúdo } \\
\text { do que vou falar } \\
\text { quando sou } \\
\text { convidado a dar } \\
\text { minhas opiniões. }\end{array}$ & $\begin{array}{c}\text { I am concern } \\
\text { with my speech } \\
\text { content when I } \\
\text { am asked to give } \\
\text { my opinion }\end{array}$ & $\begin{array}{l}\text { Eu me preocupo } \\
\text { com o conteúdo } \\
\text { do que vou falar } \\
\text { quando sou } \\
\text { convidado a dar } \\
\text { minhas opiniões. }\end{array}$ & $\begin{array}{l}\text { Eu me preocupo } \\
\text { com o conteúdo } \\
\text { do que EU vou } \\
\text { falar quando EU } \\
\text { sou convidado(a) } \\
\text { a dar minhas } \\
\text { opiniões. }\end{array}$ \\
\hline 34 & $\begin{array}{c}\text { I am not } \\
\text { concerned } \\
\text { about what other } \\
\text { people think } \\
\text { about my speech } \\
\text { content. }\end{array}$ & $\begin{array}{c}\text { EU NÃO FICO } \\
\text { PREOCUPADO } \\
\text { com o que as } \\
\text { outras pessoas } \\
\text { pensam sobre } \\
\text { O CONTEÚDO } \\
\text { DO QUE VOU } \\
\text { FALAR. } \\
\end{array}$ & $\begin{array}{c}\text { NÃO ESTOU } \\
\text { PREOCUPADO } \\
\text { com o que as } \\
\text { outras pessoas } \\
\text { pensam sobre o } \\
\text { CONTEÚDO DA } \\
\text { MINHA FALA. }\end{array}$ & $\begin{array}{c}\text { Eu não fico } \\
\text { preocupado } \\
\text { com o que as } \\
\text { outras pessoas } \\
\text { pensam sobre o } \\
\text { conteúdo do que } \\
\text { eu vou falar. }\end{array}$ & $\begin{array}{l}\text { I am not concern } \\
\text { with what people } \\
\text { think about my } \\
\text { speech content }\end{array}$ & \begin{tabular}{|} 
Eu não fico \\
preocupado \\
com o que as \\
outras pessoas \\
pensam sobre o \\
conteúdo do que \\
eu vou falar.
\end{tabular} & $\begin{array}{c}\text { Eu não fico } \\
\text { preocupado(a) } \\
\text { com o que as } \\
\text { outras pessoas } \\
\text { pensam sobre o } \\
\text { conteúdo do que } \\
\text { eu vou falar. }\end{array}$ \\
\hline 35 & $\begin{array}{l}\text { I am concerned } \\
\text { about what other } \\
\text { people think } \\
\text { about my facial } \\
\text { movement when } \\
\text { I speak. }\end{array}$ & $\begin{array}{c}\text { EU FICO } \\
\text { PREOCUPADO } \\
\text { com o que as } \\
\text { outras pessoas } \\
\text { pensam sobre o } \\
\text { MOVIMENTO } \\
\text { DE MINHA FACE } \\
\text { quando falo. } \\
\end{array}$ & $\begin{array}{c}\text { ESTOU } \\
\text { PREOCUPADO } \\
\text { com o que as } \\
\text { outras pessoas } \\
\text { pensam sobre o } \\
\text { meu MOVIMENTO } \\
\text { FACIAL quando } \\
\text { falo. } \\
\end{array}$ & $\begin{array}{c}\text { Eu fico } \\
\text { preocupado } \\
\text { com o que as } \\
\text { outras pessoas } \\
\text { pensam sobre } \\
\text { o movimento } \\
\text { da minha face } \\
\text { quando falo. } \\
\end{array}$ & $\begin{array}{l}\text { What people } \\
\text { think about my } \\
\text { face movements } \\
\text { concerns me } \\
\text { when speaking }\end{array}$ & $\begin{array}{c}\text { Eu fico } \\
\text { preocupado } \\
\text { com o que as } \\
\text { outras pessoas } \\
\text { pensam sobre } \\
\text { o movimento } \\
\text { da minha face } \\
\text { quando falo. } \\
\end{array}$ & $\begin{array}{c}\text { Eu fico } \\
\text { preocupado(a) } \\
\text { com o que as } \\
\text { outras pessoas } \\
\text { pensam sobre } \\
\text { o movimento } \\
\text { da minha face } \\
\text { quando EU falo. }\end{array}$ \\
\hline 36 & $\begin{array}{l}\text { I am concerned } \\
\text { about what other } \\
\text { people think } \\
\text { about my body } \\
\text { movement when } \\
\text { I speak. }\end{array}$ & $\begin{array}{c}\text { EU FICO } \\
\text { PREOCUPADO } \\
\text { com o que as } \\
\text { outras pessoas } \\
\text { pensam sobre } \\
\text { o movimento } \\
\text { do meu corpo } \\
\text { quando falo. }\end{array}$ & $\begin{array}{c}\text { ESTOU } \\
\text { PREOCUPADO } \\
\text { com o que as } \\
\text { outras pessoas } \\
\text { pensam sobre } \\
\text { o movimento } \\
\text { do meu corpo } \\
\text { quando falo. } \\
\end{array}$ & $\begin{array}{c}\text { Eu fico } \\
\text { preocupado } \\
\text { com o que as } \\
\text { outras pessoas } \\
\text { pensam sobre } \\
\text { o movimento } \\
\text { do meu corpo } \\
\text { quando falo. } \\
\end{array}$ & $\begin{array}{c}\text { What people } \\
\text { think about my } \\
\text { body movements } \\
\text { concerns me } \\
\text { when speaking }\end{array}$ & $\begin{array}{c}\text { Eu fico } \\
\text { preocupado } \\
\text { com o que as } \\
\text { outras pessoas } \\
\text { pensam sobre } \\
\text { o movimento } \\
\text { do meu corpo } \\
\text { quando falo. } \\
\end{array}$ & $\begin{array}{c}\text { Eu fico } \\
\text { preocupado(a) } \\
\text { com o que as } \\
\text { outras pessoas } \\
\text { pensam sobre } \\
\text { o movimento } \\
\text { do meu corpo } \\
\text { quando EU falo. } \\
\end{array}$ \\
\hline 37 & $\begin{array}{l}\text { I worry about } \\
\text { making a good } \\
\text { impression } \\
\text { with my facial } \\
\text { movement when } \\
\text { I speak. }\end{array}$ & $\begin{array}{c}\text { Eu me preocupo } \\
\text { em causar } \\
\text { uma boa } \\
\text { impressão com } \\
\text { o MOVIMENTO } \\
\text { DE MINHA FACE } \\
\text { quando falo. } \\
\end{array}$ & $\begin{array}{c}\text { Eu me preocupo } \\
\text { em causar uma } \\
\text { boa impressão } \\
\text { com A MINHA } \\
\text { MOVIMENTAÇÃo } \\
\text { FACIAL quando } \\
\text { falo. } \\
\end{array}$ & $\begin{array}{l}\text { Eu me preocupo } \\
\text { em causar } \\
\text { uma boa } \\
\text { impressão com } \\
\text { o movimento } \\
\text { da minha face } \\
\text { quando falo. }\end{array}$ & $\begin{array}{l}\text { I am concern } \\
\text { with making a } \\
\text { good impression } \\
\text { regarding my } \\
\text { face movements } \\
\text { when I speak }\end{array}$ & $\begin{array}{c}\text { Eu me preocupo } \\
\text { em causar } \\
\text { uma boa } \\
\text { impressão com } \\
\text { o movimento } \\
\text { da minha face } \\
\text { quando falo. }\end{array}$ & $\begin{array}{l}\text { Eu me preocupo } \\
\text { em causar } \\
\text { uma boa } \\
\text { impressão com } \\
\text { o movimento } \\
\text { da minha face } \\
\text { quando EU falo. }\end{array}$ \\
\hline 38 & $\begin{array}{l}\text { I care about } \\
\text { my facial } \\
\text { movement when } \\
\text { I am invited } \\
\text { to express my } \\
\text { views. }\end{array}$ & $\begin{array}{c}\text { Eu me } \\
\text { preocupo com } \\
\text { o MOVIMENTO } \\
\text { DE MINHA } \\
\text { FACE quando } \\
\text { sou CHAMADO } \\
\text { a expressar } \\
\text { MEUS PONTOS } \\
\text { DE VISTA. } \\
\end{array}$ & \begin{tabular}{|c|} 
Eu me preocupo \\
com A MINHA \\
MOVIMENTAÇÃO \\
FACIAL \\
quando sou \\
CONVIDADO \\
a expressar \\
MINHAS \\
OPINIÕES. \\
\end{tabular} & $\begin{array}{c}\text { Eu me } \\
\text { preocupo com } \\
\text { o movimento } \\
\text { da minha face } \\
\text { quando sou } \\
\text { convidado a dar } \\
\text { minhas opiniões. }\end{array}$ & $\begin{array}{l}\text { I am concern } \\
\text { with my face } \\
\text { movement when } \\
\text { I am asked to } \\
\text { give my opinion }\end{array}$ & $\begin{array}{c}\text { Eu me } \\
\text { preocupo com } \\
\text { o movimento } \\
\text { da minha face } \\
\text { quando sou } \\
\text { convidado a dar } \\
\text { minhas opiniões. }\end{array}$ & $\begin{array}{c}\text { Eu me } \\
\text { preocupo com } \\
\text { o movimento } \\
\text { da minha face } \\
\text { quando EU sou } \\
\text { convidado(a) } \\
\text { a dar minhas } \\
\text { opiniões. }\end{array}$ \\
\hline 39 & $\begin{array}{c}\text { I do not worry } \\
\text { about making a } \\
\text { good impression } \\
\text { with my facial } \\
\text { movement when I } \\
\text { speak. }\end{array}$ & \begin{tabular}{|c|} 
Eu não me \\
preocupo em \\
causar uma boa \\
impressão com os \\
MOVIMENTOS \\
DE MINHA FACE \\
quando falo. \\
\end{tabular} & $\begin{array}{c}\text { Não me preocupo } \\
\text { em causar uma } \\
\text { boa impressão } \\
\text { com a minha } \\
\text { MOVIMENTAÇÃo } \\
\text { FACIAL quando } \\
\text { falo. }\end{array}$ & $\begin{array}{l}\text { Eu não me } \\
\text { preocupo em } \\
\text { causar uma boa } \\
\text { impressão com } \\
\text { os movimentos } \\
\text { da minha face } \\
\text { quando falo. }\end{array}$ & $\begin{array}{l}\text { I am not concern } \\
\text { with making a } \\
\text { good impression } \\
\text { regarding my } \\
\text { face movements } \\
\text { when I speak }\end{array}$ & $\begin{array}{c}\text { Eu não me } \\
\text { preocupo em } \\
\text { causar uma boa } \\
\text { impressão com } \\
\text { os movimentos } \\
\text { da minha face } \\
\text { quando falo. }\end{array}$ & $\begin{array}{c}\text { Eu não me } \\
\text { preocupo em } \\
\text { causar uma boa } \\
\text { impressão com } \\
\text { os movimentos } \\
\text { da minha face } \\
\text { quando EU falo. }\end{array}$ \\
\hline
\end{tabular}

Fonte: elaborada pelos autores 


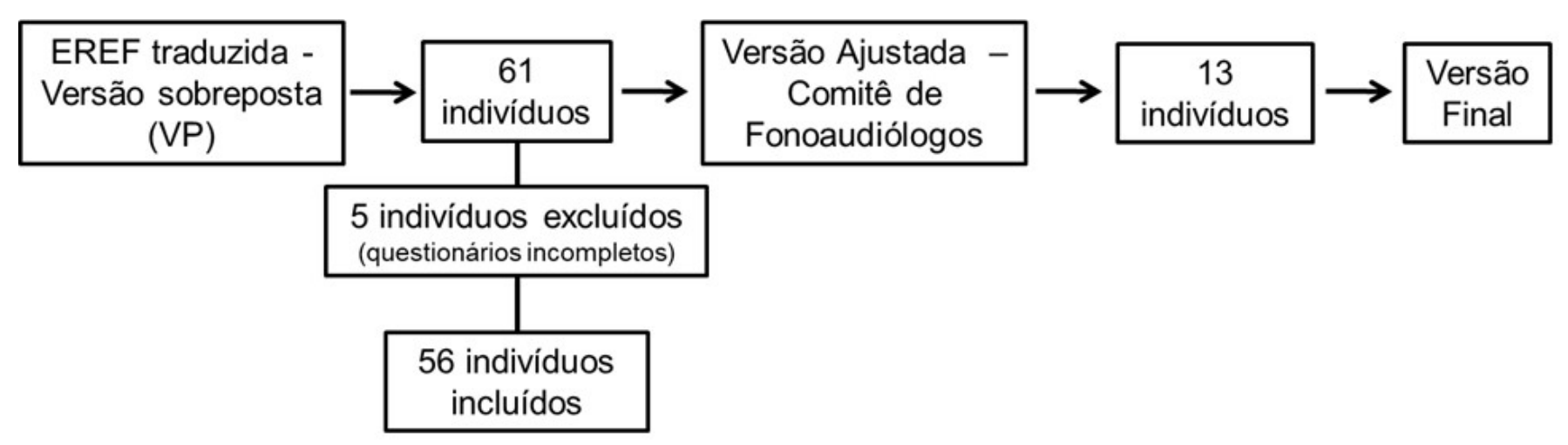

Figura 1. Organograma de preenchimento do questionário da pesquisa e inclusão e exclusão de sujeitos

A composição final da versão brasileira traduzida e culturalmente adaptada do SSRS, chamada de EREF (Anexo 1), apresenta 39 itens, como o protocolo original.

\section{DISCUSSÃO}

A comunicação desempenha um grande poder dentro da sociedade atual. Utilizando a comunicação, podemos convencer, persuadir, influenciar, despertar interesses e sentimentos, e ainda provocar expectativas no interlocutor ${ }^{(11)}$. Dentro de uma organização, por exemplo, a comunicação bem utilizada pode estabelecer relações pacíficas, homogeneização e integração de ideias. A comunicação é um meio e também uma ferramenta e tendo em vista o seu papel fundamental, é importante que exista como avaliá-la, em seus diferentes aspectos. Para essa finalidade, a SSRS foi criada.

Quando um novo protocolo é proposto, existem regras no seu desenvolvimento para que não haja dificuldades na sua aplicação com a população alvo. $\mathrm{O}$ mesmo deve ser pensado para a utilização deste protocolo em outros países e, por isso, a validação do protocolo para cada língua e cultura é essencial. A obtenção da equivalência cultural é a primeira etapa para a validação de protocolos e visa a eliminação de barreiras culturais e linguísticas entre o instrumento e sua população alvo em diferentes países ${ }^{(10)}$. O modelo de equivalência cultural utilizado para esta pesquisa já foi realizado com sucesso em validações de outros protocolos no Brasil ${ }^{(12-15)}$.

A equivalência cultural da SSRS iniciou-se com a adaptação cultural e linguística, na qual é aplicada a versão da escala para a equivalência semântica e do idioma. Nessa fase, 27 questões foram identificadas como não compreendidas ou não apropriadas para a população alvo e cultura brasileira e foram discutidas pelo comitê de Fonoaudiólogos. O alto número de questões com barreiras para a população alvo (69\%) levantou a discussão por parte do Comitê de Fonoaudiólogos a respeito do entendimento da escala por parte da população alvo. Foi observado que muitos respondentes não haviam compreendido a real função da opção "não aplicável" e em vez de assinalá-la quando acreditavam que a questão não era adequada à escala, alguns estavam assinalando essa opção por não realizarem o contexto da questão em suas tarefas de comunicação. Ou seja, em vez de responder à questão seguindo a frequência de respostas de 1 a 6 , os respondentes assinalavam "não aplicável”. Essa situação levou à necessidade de rever as instruções para preenchimento da escala e, em nova aplicação, não foram observadas dificuldades.

A etapa de adaptação cultural é essencial para que a linguagem da escala se aproxime da população alvo e para que a consistência da forma de comunicação seja mantida em todas as questões. Essa etapa deve ser realizada quantas vezes for preciso até que a escala/o protocolo seja aceito pela população alvo. A SRSS para o português brasileiro precisou de duas revisões para que fosse aceita.

Com a conclusão do processo de equivalência cultural e linguística para o Português Brasileiro, terá início o processo de validação da EREF, nome da escala adaptada. Seu uso será importante, visto que a maioria dos protocolos de autoavaliação de voz é direcionada para doenças específicas, não são adequados para indivíduos com vozes saudáveis e não contemplam outras questões de comunicação oral. A SSRS é uma escala específica para profissionais da voz e será fundamental no Brasil para avaliar quem utiliza a voz como seu instrumento de trabalho independentemente do nível de classificação do uso profissional da voz.

\section{CONCLUSÃO}

Foi verificada equivalência cultural entre a SSRS e a sua versão traduzida para o português brasileiro, a EREF. Sendo assim, será dado início às outras de validação da EREF para o português brasileiro.

\section{REFERÊNCIAS}

1. Nöth W. Comunicação: os paradigmas da simetria, antissimetria e assimetria. Matrizes. 2011;1:85-108. https://doi.org/10.11606/issn.19828160.v5i1p85-107.

2. Svec JG, Behlau M. April 16th: the World Voice Day. Folia Phoniatr Logop. 2007;59(2):53-4. http://dx.doi.org/10.1159/000098337. PMid:17337894.

3. Ruben RJ. Redefining the survival of the fittest:communication disorders in the 21 st century. Laryngoscope. 2000;110(2 Pt 1):241-5. http://dx.doi. org/10.1097/00005537-200002010-00010. PMid:10680923. 
4. WHO: World Health Organization. WHOQOL. Measuring Quality of Life. The World Health Organization Quality of Life Instruments (THE WHOQOL-100 AND THE WHOQOL-BREF). Geneva: WHO; 1997.

5. Lo ESC, Wong AWK, Tse ACY, Ma EPM, Whitehill TL, Masters RSW. Development of a psychometric measure of the propensity to consciously control and monitor speech production. J Speech Lang Hear Res. 2020;63(4):963-82. http://dx.doi.org/10.1044/2020_JSLHR-19-00365. PMid:32310711.

6. Masters RSW. Knowledge, knerves and know-how: the role of explicit versus implicit knowledge in the breakdown of a complex motor skill under pressure. Br J Psychol. 1992;83(3):343-58. http://dx.doi.org/10.1111/j.2044-8295.1992. tb02446.x.

7. Masters RS, Polman RC, Hammond NV. "Reinvestment": A dimension of personality implicated in skill breakdown under pressure. Pers Individ Dif. 1993;14(5):655-66. http://dx.doi.org/10.1016/0191-8869(93)90113-H.

8. Masters RS, Maxwell J. The theory of reinvestment. Int Rev Sport Exerc Psychol. 2008;1(2):160-83. http://dx.doi.org/10.1080/17509840802287218.

9. Malhotra N, Poolton JM, Wilson MR, Uiga L, Masters RSW. Examining movement-specific reinvestment and performance in demanding contexts. J Sport Exerc Psychol. 2015;37(3):327-38. http://dx.doi.org/10.1123/ jsep.2014-0220. PMid:26265344.

10. Aaronson N, Alonso J, Burnam A, Lohr KN, Patrick DL, Perrin E, et al. Assessing health status and quality-of-life instruments: attributes and review criteria. Qual Life Res. 2002;11(3):193-205. http://dx.doi. org/10.1023/A:1015291021312. PMid:12074258.
11. Pinheiro DCS. O papel do plano de comunicação preventivo em momento de crise na organização [Trabalho de Conclusão de Curso]. Goiânia: Faculdade de Informação e Comunicação, Universidade Federal de Goiás; 2005.

12. Gasparini G, Behlau M. Quality of Life: Validation of the Brazilian Version of the Voice-Related Quality-of-Life (V-RQOL) Measure. J Voice. 2009;23(1):76-81. http://dx.doi.org/10.1016/j.jvoice.2007.04.005. PMid:17628396.

13. Costa T, Oliveira G, Behlau M. Validation of the Voice Handicap Index: 10 (VHI-10) to the Brazilian Portuguese. CoDAS. 2013;25(5):482-5. http:// dx.doi.org/10.1590/S2317-17822013000500013. PMid:24408554.

14. Moreti F, Zambon F, Oliveira G, Behlau M. Cross-cultural adaptation, validation, and cutoff values of the Brazilian version of the Voice Symptom Scale-VoiSS. J Voice. 2014;28(4):458-68. http://dx.doi.org/10.1016/j. jvoice.2013.11.009. PMid:24560004.

15. Behlau M, Rocha BR, Englert M, Madazio G. Validation of the Brazilian Portuguese CAPE-V Instrument-Br CAPE-V for Auditory-Perceptual Analysis. J Voice. 2020. In press. https://doi.org/10.1016/j.jvoice.2020.07.007.

\section{Contribuição dos autores}

BRR foi responsável pela concepção do estudo, coleta, tabulação, análise e interpretação dos dados e elaboração do manuscrito; $A W W$ e EPM participaram da idealização do estudo e interpretação dos dados; $M B$, na condição de orientadora, foi responsável pela proposta e concepção do estudo, análise e interpretação dos dados e revisão final do manuscrito. 
Anexo 1. Versão traduzida e culturalmente adaptada da escala Speech-Specific Reinvestment Scale - SSRS, chamada Escala de Reinvestimento Específico da Fala - EREF

Pergunta 1 a 39: As frases a seguir descrevem sua autorreflexão enquanto fala no português brasileiro.

As questões precisam ser lidas com atenção. Algumas são positivas e outras negativas.

Selecione as opções mais adequadas para indicar o quanto você concorda com cada uma das questões:

1: Discordo totalmente

2: Discordo

3: Discordo ligeiramente

4: Concordo ligeiramente

5: Concordo

6: Concordo totalmente

(Nota: Não há resposta certa ou errada para cada frase)

\begin{tabular}{|c|c|c|c|c|c|c|c|}
\hline & \multirow[b]{2}{*}{ Eu avalio o movimento da minha boca quando eu falo. } & \multicolumn{4}{|c|}{$\begin{array}{l}\text { Discordo } \\
\text { Totalmente }\end{array}$} & \multicolumn{2}{|c|}{$\begin{array}{r}\text { Concordo } \\
\text { Totalmente }\end{array}$} \\
\hline 1 & & 1 & 2 & 3 & 4 & 5 & 6 \\
\hline 2 & Eu percebo como a minha boca se move quando eu falo. & 1 & 2 & 3 & 4 & 5 & 6 \\
\hline 3 & Eu dedico tempo para refletir sobre o movimento da minha boca depois de falar. & 1 & 2 & 3 & 4 & 5 & 6 \\
\hline 4 & Eu dedico tempo para pensar no movimento da minha boca antes de falar. & 1 & 2 & 3 & 4 & 5 & 6 \\
\hline 5 & Eu penso no movimento dos meus lábios quando eu falo. & 1 & 2 & 3 & 4 & 5 & 6 \\
\hline 6 & Eu penso no movimento da minha língua quando eu falo. & 1 & 2 & 3 & 4 & 5 & 6 \\
\hline 7 & Eu penso no movimento da minha mandíbula quando eu falo. & 1 & 2 & 3 & 4 & 5 & 6 \\
\hline 8 & Eu penso no movimento da minha laringe quando eu falo. & 1 & 2 & 3 & 4 & 5 & 6 \\
\hline 9 & Eu tento descobrir como o movimento da minha boca gera a pronúncia das palavras. & 1 & 2 & 3 & 4 & 5 & 6 \\
\hline 10 & Eu repenso em como o movimento da minha boca me ajudou a falar sem dificuldades. & 1 & 2 & 3 & 4 & 5 & 6 \\
\hline 11 & Eu penso em como o movimento da minha boca me ajudou a falar sem dificuldades. & 1 & 2 & 3 & 4 & 5 & 6 \\
\hline 12 & Eu tento entender como minha fala surge do movimento da minha boca. & 1 & 2 & 3 & 4 & 5 & 6 \\
\hline 13 & Eu percebo como minha boca se move para o que eu quero falar. & 1 & 2 & 3 & 4 & 5 & 6 \\
\hline 14 & Eu não tento descobrir como o movimento da minha boca gera a pronúncia das palavras. & 1 & 2 & 3 & 4 & 5 & 6 \\
\hline 15 & Eu me preocupo com a voz que eu uso para me apresentar aos outros. & 1 & 2 & 3 & 4 & 5 & 6 \\
\hline 16 & Antes de falar com outras pessoas, eu penso como está minha pronúncia. & 1 & 2 & 3 & 4 & 5 & 6 \\
\hline 17 & Eu me preocupo com a minha pronúncia quando eu sou convidado a dar minhas opiniões. & 1 & 2 & 3 & 4 & 5 & 6 \\
\hline 18 & Eu fico preocupado(a) com o que as outras pessoas pensam sobre o volume da minha fala. & 1 & 2 & 3 & 4 & 5 & 6 \\
\hline 19 & $\begin{array}{l}\text { Eu me preocupo com o volume da minha fala quando eu estou me apresentando para outras } \\
\text { pessoas. }\end{array}$ & 1 & 2 & 3 & 4 & 5 & 6 \\
\hline 20 & Eu me preocupo em causar uma boa impressão no volume da minha fala. & 1 & 2 & 3 & 4 & 5 & 6 \\
\hline 21 & Antes de falar com outras pessoas, eu penso no volume da minha fala. & 1 & 2 & 3 & 4 & 5 & 6 \\
\hline 22 & Eu me preocupo com o volume da minha fala quando eu sou convidado(a) a dar minha opinião. & 1 & 2 & 3 & 4 & 5 & 6 \\
\hline 23 & Eu fico preocupado(a) com o que as outras pessoas pensam sobre a velocidade da minha fala. & 1 & 2 & 3 & 4 & 5 & 6 \\
\hline 24 & $\begin{array}{l}\text { Eu me preocupo com a velocidade da minha fala quando eu estou me apresentando para outras } \\
\text { pessoas. }\end{array}$ & 1 & 2 & 3 & 4 & 5 & 6 \\
\hline 25 & Eu me preocupo em causar uma boa impressão com a velocidade da minha fala. & 1 & 2 & 3 & 4 & 5 & 6 \\
\hline 26 & Antes de falar com outras pessoas, eu penso na velocidade da minha fala. & 1 & 2 & 3 & 4 & 5 & 6 \\
\hline 27 & Eu me preocupo com a velocidade da minha fala quando eu sou convidado a dar minha opinião. & 1 & 2 & 3 & 4 & $\mathbf{5}$ & 6 \\
\hline 28 & Antes de falar com outras pessoas, eu não penso em como está minha pronúncia das palavras. & 1 & 2 & 3 & 4 & $\mathbf{5}$ & 6 \\
\hline 29 & Eu fico preocupado com o que as outras pessoas pensam sobre o conteúdo da minha fala. & 1 & 2 & 3 & 4 & 5 & 6 \\
\hline 30 & $\begin{array}{l}\text { Eu me preocupo com a organização do conteúdo do que eu vou falar ao me apresentar para outras } \\
\text { pessoas. }\end{array}$ & 1 & 2 & 3 & 4 & 5 & 6 \\
\hline 31 & Eu me preocupo em causar uma boa impressão com o conteúdo da minha fala. & 1 & 2 & 3 & 4 & $\mathbf{5}$ & 6 \\
\hline 32 & Antes de falar com outras pessoas, eu penso no conteúdo do que eu vou falar. & 1 & 2 & 3 & 4 & $\mathbf{5}$ & 6 \\
\hline 33 & $\begin{array}{l}\text { Eu me preocupo com o conteúdo do que eu vou falar quando eu sou convidado(a) a dar minhas } \\
\text { opiniões. }\end{array}$ & 1 & 2 & 3 & 4 & 5 & 6 \\
\hline 34 & $\begin{array}{l}\text { Eu não fico preocupado(a) com o que as outras pessoas pensam sobre o conteúdo do que eu vou } \\
\text { falar. }\end{array}$ & 1 & 2 & 3 & 4 & 5 & 6 \\
\hline 35 & $\begin{array}{l}\text { Eu fico preocupado(a) com o que as outras pessoas pensam sobre o movimento da minha face } \\
\text { quando eu falo. }\end{array}$ & 1 & 2 & 3 & 4 & $\mathbf{5}$ & 6 \\
\hline 36 & $\begin{array}{l}\text { Eu fico preocupado(a) com o que as outras pessoas pensam sobre o movimento do meu corpo } \\
\text { quando eu falo. }\end{array}$ & 1 & 2 & 3 & 4 & 5 & 6 \\
\hline 37 & Eu me preocupo em causar uma boa impressão com o movimento da minha face quando eu falo. & 1 & 2 & 3 & 4 & 5 & 6 \\
\hline 38 & $\begin{array}{l}\text { Eu me preocupo com o movimento da minha face quando eu sou convidado(a) a dar minhas } \\
\text { opiniões. }\end{array}$ & 1 & 2 & 3 & 4 & 5 & 6 \\
\hline 39 & $\begin{array}{l}\text { Eu não me preocupo em causar uma boa impressão com os movimentos da minha face quando } \\
\text { eu falo. }\end{array}$ & 1 & 2 & 3 & 4 & $\mathbf{5}$ & 6 \\
\hline
\end{tabular}

